\title{
PSYCHOLOGICAL WELL BEING AND ADJUSTMENT OF SINGLE PARENTS: PSYCHO- SOCIALAND ECONOMIC CHALLENGES
}

\author{
Amina Hanif Tarar, Huma Asghar*, Muhammad Mohsin Ijaz, Muhammad Ali Tarar** \\ Government College University Lahore Pakistan, *Kinnaird College for Women University, Lahore Pakistan, ${ }^{* *}$ Gazi University, Dera Ghazi \\ Khan Pakistan
}

\begin{abstract}
Objective: To explore the relationship between psychological well-being and psycho-social adjustment of economically independent and dependent single parents belonging to various socio-economic classes.

Study Design: Correlational study.

Place and Duration of Study: This study was conducted at technical services association, Lahore, from Jun 2018 to Aug 2019.

Methodology: A sample of 213 single parents with ages ranging from 25 to 50 was selected through purposive sampling. Psychological Well-Being Scale Revisited and Psychological Adjustment Scale were used.

Results: Multivariate analysis showed that well-being and adjustment levels of divorced $(\mathrm{M}=114.17, \mathrm{SD}=24.5)$, $(\mathrm{M}=88.89, \mathrm{SD}=19.45)$ single parents was significantly lower than those of widowed $(\mathrm{M}=136.78, \mathrm{SD}=17.68)$, $(\mathrm{M}=105.86, \mathrm{SD}=10.88)$ ones respectively. Also, economically independent $(\mathrm{M}=135.1, \mathrm{SD}=20.38),(\mathrm{M}=104.0, \mathrm{SD}=$ 14.5) single parents had better well-being and adjustment than those who are economically dependent $(\mathrm{M}=108.3$, $\mathrm{SD}=24.5),(\mathrm{M}=85.5, \mathrm{SD}=17.1)$. Furthermore, post-hoc tests revealed significantly low psychological well-being $(\mathrm{M}=130.72, \mathrm{SD}=23.16)$ and adjustment $(\mathrm{M}=81, \mathrm{SD}=12.23)$ of single parents from lower social class.

Conclusion: The study concludes that socio-economic status and economic independence/dependence have a profound impact on the psychological wellbeing and adjustment of single parents. These findings will promote the understanding of single parenting in collectiveistic cultures and may lead towards learning of coping strategies to foster psychological well-being, familial and social adjustments of single parents.
\end{abstract}

Keywords: Adjustment, Psychological well being, Single parenting.

This is an Open Access article distributed under the terms of the Creative Commons Attribution License (http://creativecommons.org/licenses/by/4.0), which permits unrestricted use, distribution, and reproduction in any medium, provided the original work is properly cited.

\section{INTRODUCTION}

Among several rapid changes that took place in the $20^{\text {th }}$ century, one of the drastic ones was the breakdown of traditional family structure. During the last few decades, the number of singleparent families increased rapidly. Today, worldwide, single-parent families represent about a quarter of all the families. Single-parent families are those where one parent, mother or father, lives with dependent children without a partner, either by her/himself or in an extended household. Single-parent families are increasing in Pakistan $(6 \%)^{1}$ as well despite that the cultural values of a highly religious country emphasize marital and familial unity.

Single parenting are prone to calamitous and

Correspondence: Dr Amina Hanif Tarar, Dept of Psychology, Government College University, Lahore Pakistan

Received: 22 Aug 2020; revised received: 11 Nov 2020; accepted: 18 Nov 2020 stressful and anxiety provoking events, which in turn, also effect their psychological well being. For instance, divorce leads not only to numerous economic and employment challenges, but also social loneliness and physical health issues. A socially acceptable prerequisite is always considered marriage and can be most conspicuous in a high collectivistic society like Pakistan where marital success provides the basic matrix of all other social relations. Likewise, death of a spouse is assumed as life's most painful events and widowhood also drastically influence well-being of an individual ${ }^{2}$. Literature is also evident that women face more trauma, pain, and even cognitive decline after losing a spouse as compared to men ${ }^{3}$. Additionally, women are less likely than men to remarry, and men rather take this decision quic$\mathrm{ker}^{4}$. Although financial hardship after widowhood is generally presumed harsh for women, economic difficulty along with work stress, social 
and emotional crisis are significantly observed in single parents of both genders 5 . Both divorce and death of a spouse are traumas where the single parent not only endure grief and impediments her/himself but also has to redeem her/his children who share the loss of a parent. Also, single parents feel more difficulty in coping with childrearing because responsibility is multiplied ${ }^{6}$.

Single parenting is a severe challenge in a highly collectivistic culture of Pakistan where norms favour traditional family. Amidst possible stigmatization from society, as well as coping with loss, supporting one's children financially and emotionally poses threats to psychological well-being and adjustment within the family. The rationale of this research follows that previous studies explored the differences between singleparent families with the traditional ones (i.e., a mother, father and children) ${ }^{7}$, and few efforts have concentrated on the psychological differences with-in the single parent's group ${ }^{8}$. Therefore, a need has arisen to study the variability among single-parents' mental health in terms of psychological well being and adjustment. Psychological well being and adjustment are both multi-dimensional constructs. Psychological well-being comprises of "autonomy (a sense of self-determination), environmental mastery (the capacity to manage effectively own life and surroundings), personal growth, positive relations with others, purpose in life, and self-acceptance (positive evaluation of oneself and one's past life)" ${ }^{\prime 2}$. Psychological Adjustment is "the ability to have an accurate perception of reality, the ability to cope with stress and anxiety, a positive self-image, the ability to express the full range of emotions and to have good interpersonal skills"10. Significant differences in the psychological well being and adjustment of single parents on the basis of socioeconomic status, economic independence and dependence, divorced and widowed status and gender were predicted.

\section{METHODOLOGY}

The study was conducted at technical servies association (TSA) from June, 2018 to August,
2019. The study employed a correlational design using a survey method to gain observations on The sample was drawn with purposive sampling technique. The inclusion criteria were an only mother or father living with her/his children in the nuclear or extended family system with other relatives. Single parents whose divorce was under process and who were not divorced but separated were excluded from study. The data from upper class single parents was collected from TSA assistance through snowballing as they were not directly associated with the organization for any support. The ethical principles as informed consent, the confident-iality of the participant, providing them with knowledge of the purpose of the study and ensuring access to any publications upon their demand were thoroughly followed. Certification of following ethics standards was approved from relevant authorities (Certificate No. TSA/Sep/19/7). Ryff's psychological well-being Revisited ${ }^{9}$ was used to measure the psychological well-being of single parents. It consists of 6 distinct subscales of wellness that is Autonomy (a sense of self-determination), Environmental mastery (the capacity to manage surroundings), Personal growth, Positive relations, Purpose in life, and Self-acceptance (positive evaluation of oneself and one's past life). Responses on the scale were elicited on a six-point scale ranging from strongly disagree to strongly agree. There are positive and negative phrased items on inventory. The negatively phrased items were scored reversely. Psychological Adjustment Scale is an indigenous scale in the Urdu language ${ }^{11}$. It was used to measure adjustment levels. This inventory consists of 27 items. It explores different aspects of adjustment that are: accurate perception of reality, ability to cope with stress and anxiety, positive self-image, ability to express the full range of emotions and good interpersonal relationships. Each item on the scale was scored on a five-point rating ranging from strongly disagree to strongly agree. There were negative and positive statements on the scale. Negative items were reversed scored. Both instruments had wellestablished reliability and other psychometric 
properties reported by their authors and numerous other studies. Data were analysed using SPSS package 21 employing statistical techniques of $t$-test and MANOVA.

\section{RESULTS}

A sample consisting of 213 single parents participated in the study, comprising of 102 $(47.9 \%)$ men and 111 (52.1\%) women. Age of single parents varied from 21 to 50 with 21-30 $(29.6 \%), 31-40(27.7 \%)$, and 41-50 (42.7\%). Seventy eight $(36.6 \%)$ single parents were from lower, 69 $(32.4 \%)$ from middle and $66(31 \%)$ were from trated very high internal consistency. A $t$-test indicated no significant gender differences among single parents, psychological well-being and adjustment. The results of multivariate tests (table-I) indicated that the main effect of single parent case type (divorced/widowed) (Wilk's Lambda $\lambda=0.85)$, Economic independence/dependence (Wilk's Lambda $\lambda=0.90$ ), and Socio-economic status (Wilk's Lambda $\lambda=0.92$ ) were statistically significant on single parent's psychological well being and adjustment. The interaction effects were not the focal point here.

Results indicated a significant main effect of

Table-I: Multivariate analysis of variance to explore the single parents' psychological well-being and adjustment in terms of divorce/widowed, economic dependence / independence, and Socio-economic status ( $\mathrm{n}=213)$.

\begin{tabular}{|c|c|c|c|c|c|c|c|c|}
\hline Source & Dependent Variable & $\begin{array}{l}\text { Sum of } \\
\text { squares }\end{array}$ & $\begin{array}{c}\text { Degree } \\
\text { of } \\
\text { Freedom }\end{array}$ & $\begin{array}{l}\text { Mean } \\
\text { Square }\end{array}$ & $\mathbf{F}$ & $p$-value & $\eta \mathrm{P} 2$ & $\begin{array}{c}\text { Obser- } \\
\text { ved } \\
\text { Power }\end{array}$ \\
\hline \multirow{2}{*}{ Case type } & Psychological well-being & 10814.18 & 1 & 10814.18 & 34.55 & $<0.01^{*}$ & .15 & 1.00 \\
\hline & Psychological Adjustment & 1131.24 & 1 & 1131.24 & 13.06 & $<0.01^{* *}$ & .06 & .95 \\
\hline \multirow{2}{*}{ Economy } & Psychological well-being & 6529.32 & 1 & 6529.32 & 20.86 & $<0.01^{* *}$ & .09 & 1.00 \\
\hline & Psychological Adjustment & 1648.36 & 1 & 1648.36 & 19.04 & $<0.01^{* *}$ & .09 & .99 \\
\hline \multirow{2}{*}{$\begin{array}{l}\text { Socio- } \\
\text { economic } \\
\text { Status }\end{array}$} & Psychological well-being & 4104.60 & 2 & 2052.30 & 6.56 & $<0.01^{\star *}$ & .06 & .91 \\
\hline & Psychological Adjustment & 582.57 & 2 & 291.28 & 3.36 & $.037^{*}$ & .03 & .63 \\
\hline \multirow{2}{*}{$\begin{array}{l}\text { Case type* } \\
\text { Economy }\end{array}$} & Psychological well-being & 2176.52 & 1 & 2176.52 & 6.95 & $<0.01^{* *}$ & .03 & .75 \\
\hline & Psychological Adjustment & 20.12 & 1 & 20.12 & .23 & .630 & .00 & .08 \\
\hline \multirow{2}{*}{$\begin{array}{l}\text { Case type* } \\
\text { SES }\end{array}$} & Psychological well-being & 7221.74 & 2 & 3610.87 & 11.53 & $<0.01^{* *}$ & .10 & .99 \\
\hline & Psychological Adjustment & 1078.12 & 2 & 539.06 & 6.23 & $<0.01^{* *}$ & .06 & .89 \\
\hline \multirow{2}{*}{ Economy* SES } & Psychological well-being & 10823.38 & 2 & 5411.69 & 17.29 & $<0.01^{* *}$ & .15 & 1.00 \\
\hline & Psychological Adjustment & 583.81 & 2 & 291.90 & 3.37 & $0.036^{*}$ & .03 & .63 \\
\hline \multirow{2}{*}{$\begin{array}{l}\text { Case type* } \\
\text { Economy* SES }\end{array}$} & Psychological well-being & 249.10 & 1 & 249.10 & .80 & 0.373 & .00 & .14 \\
\hline & Psychological Adjustment & 42.33 & 1 & 42.33 & .49 & 0.485 & .00 & .11 \\
\hline \multirow{2}{*}{ Error } & Psychological well-being & 63234.71 & 202 & 313.04 & - & - & - & - \\
\hline & Psychological Adjustment & 17492.26 & 202 & 86.60 & - & - & - & - \\
\hline \multirow{2}{*}{ Total } & Psychological well-being & 4991125 & 213 & - & - & - & - & - \\
\hline & Psychological Adjustment & 1709353 & 213 & - & - & - & - & - \\
\hline
\end{tabular}

upper socio-economic status. Fifty nine $(27.7 \%)$ were matriculates/intermediate, 68 (31.9\%) bachelors, and $86(40.4 \%)$ masters. One hundred and thirty four $(62.9 \%)$ were economically independent and $79(37.1 \%)$ were dependent. One hundred and nine $(51.2 \%)$ were divorced and 104 $(48.8 \%)$ were widowed.

The reliabilities in terms of internal consistency were calculated. Both measures, Ryff's psychological well-being Revisited $(\alpha=.90)$ and Psychological Adjustment Scale $(\alpha=.84)$ demons-
Case type (divorced/widowed) on single parent's psychological well-being $(\mathrm{F}(1,213)=34.55$, ìp2 $=$ $0.15, p<0.001)$ and psychological adjustment (F $(1,213)=13.06$, nंp2=.06, $p<.001)$. Partial eta squared indicated that Case type (divorced/widowed) was responsible for $15 \%$ variance in single parent's psychological wellbeing and 6\% variance in adjustment. Next, results indicated a significant main effect of Economic independence/ dependence on single parent's psychological wellbeing $(F(1,213)=20.86$, ทेp2=.09, $p<.001)$ and 
psychological adjust-ment $(\mathrm{F}(1,213)=19.04$, n்p2 $=.09, p<.001)$. Partial eta Squared indicated that Economic independence/dependence was responsible for $9 \%$ variance in single parent's psychological wellbeing and 9\% variance in adjustment.
Further, post hoc analysis (table-IV) revealed that single parents from lower socio-economic class scored significantly lower on psychological well-being and adjustment than the rest.

Table-II: Mean, standard deviation and pairwise comparisons for divorced and widowed single parents.

\begin{tabular}{l|c|c|c|c}
\hline \multirow{2}{*}{ Variables } & Divorced (n=109) & Widowed (n=104) & \multirow{2}{*}{ F } & \multirow{2}{*}{ Pairwise Comparisons } \\
\cline { 2 - 3 } & Mean \pm SD & Mean \pm SD & & $2>1$ \\
\hline Psychological well-being & $138.61 \pm 25.43$ & $163.36 \pm 22.47$ & 34.55 & $2>1$ \\
\hline Psychological Adjustment & $84.52 \pm 14.21$ & $93.13 \pm 8.08$ & 13.06 & \\
\hline
\end{tabular}

Table-III: Mean, standard deviation and pairwise comparisons for economically independent and dependent single parents.

\begin{tabular}{l|c|c|c|c}
\hline Variables & $\begin{array}{c}\text { Economically Independent } \\
\mathbf{( n = 1 3 4 )}, \text { Mean } \pm \text { SD }\end{array}$ & $\begin{array}{c}\text { Economically Dependent } \\
(\mathbf{n = 7 9 )}, \text { Mean } \pm \text { SD }\end{array}$ & $\mathbf{F}$ & $\begin{array}{c}\text { Pairwise } \\
\text { Comparisons }\end{array}$ \\
\hline Psychological well-being & $161.79 \pm 22.75$ & $131.86 \pm 22.94$ & 20.86 & $1>2$ \\
\hline Psychological Adjustment & $93.75 \pm 10.45$ & $80.20 \pm 10.65$ & 19.04 & $1>2$ \\
\hline
\end{tabular}

Table-IV: Mean, standard deviation and f-values for upper, middle and low socio-economic class.

\begin{tabular}{|l|c|c|c|c|c}
\hline Variables & $\begin{array}{c}\text { Upper Class (n=66) } \\
\text { Mean } \pm \text { SD }\end{array}$ & $\begin{array}{c}\text { Middle Class (n=69) } \\
\text { Mean } \pm \text { SD }\end{array}$ & $\begin{array}{c}\text { Low Class (n=78) } \\
\text { Mean } \pm \text { SD }\end{array}$ & F & Post Hoc \\
\hline Psychological well-being & $160.56 \pm 22.23$ & $163.83 \pm 21.54$ & $130.72 \pm 23.16$ & 49.46 & $2>1>3$ \\
\hline Psychological Adjustment & $95.53 \pm 10.70$ & $90.96 \pm 8.97$ & $81.00 \pm 12.23$ & 36.62 & $1>2>3$ \\
\hline
\end{tabular}

More, results indicated a significant main effect of socioeconomic status on single parent's psychological well-being $(\mathrm{F}(2,213)=6.56$, ǹp2 $=.06$, $p<.001)$ and psychological adjustment $(\mathrm{F}(2,213)=$ 3.36, ทे $2=03, p<.001)$. Partial eta Squared indicated that Socio-economic status was responsible for $6 \%$ variance in single parent's psychological wellbeing and 3\% variance in adjustment. Observed power of the tests were very high for all the main effects of case type (divorced/widowed), Economic independence/dependence, socio-economic status on both psychological wellbeing and adjustment indicating that tests were able to detect the difference if it was there.

Table-II shows the further exploration by pairwise comparisons revealing higher mean scores for Widowed single parents on psychological wellbeing and adjustment as compared to Divorced ones.

Table-III shows the further exploration by pairwise comparisons revealing higher means scores for Economically Independent single parents on psychological wellbeing and adjustment as compared to Economically Dependent ones.

\section{DISCUSSION}

The present study was designed to explore the mental health of single parents in terms of psychological well-being and adjustment. The results of the study supported the hypotheses. Except for gender, there were significant differences in the adjustment and well-being of single parents according to their economic independence and dependence and divorced and widowed status.

The results supported significant differences in psychological adjustment and wellbeing among single parents belonging to various socioeconomic statuses. This, therefore, reinstates the role of economics in the adjustment of single parents who, as a result of changes infamily structure, have to face economic pressures. These results support earlier research where interviews with single parents revealed economic circumstances to be a major contributor to their distress ${ }^{12}$. Well-off single parents can, thus, nurture their children better as compared to those stuck at lower levels of socio-economic scaleor dependent on others for daily needs. Furthermore, earlier studies reveal financial constraints and the 
realization of the lack of a provider to modify the relationship between widowhood and depressive symptoms ${ }^{13}$. Therefore, economic hardship perturbsthe well-being and adjustment of impecunious ones.

There were significant differences between economically independent and dependent single parents on psychological well-being and adjustment. Similar toother research efforts showing how balancing employment with childcare helps lone parenting in single mothers, the current study also demonstrated higher psychological well-being and adjustment levels of employed single mothers. However, maternal employment has a positive effect up to an extent, as workload and job stress can exacerbate the situation when thesingle parents struggle to manage quality time at home ${ }^{14}$.

Moreover, substantial differences between the well-being of economically independent and dependent single parents also illustrate the collectivistic to individualistic transitioning of Pakistani society ${ }^{15}$. A few decades ago, burdens were abated by family as compared to current circumstances; families continued to live together in a monied sense as well. The ceaseless shattering of traditional, integrated and joint-familyis inciting individual economic hardships. Therefore, single parents may experience economic dependence asa repercussion for their self-esteem, and consequently, well-being. This is supported by earlier research showing that amidst financial hardships, social support can be a protective factor in transitions of widowhood ${ }^{16}$.

Divorced and widowed single parents differed significantly on psychological well-being and adjustment with the latter scoring higher on both variables. The influence of a collectivist culture is accentuated with widowed single parents reporting better adjustment and well-being than divorced ones. These results can be understood in acontext where divorce is a stigma. Nonetheless, widowed single parents face economic challenges, yet divorced ones are the special targets of social stigmatization. Pakistani culture is ahighly religious and collectivist one, where the separation between couples elicits many social pressures17, delineating their discounted social adjustment and well-being scores. Divorced single parents live with the unfinished business of a previous relationship that is further amplified by the social stigmatization. The unfinished business remnants come as court trials, child custody cases and inefficient court systems which may pose further challenges to the well-being and adjustment of single parents ${ }^{18}$.

Like any other scientific investigation, this study also has some limitations. First, our sample may have over/under-represented the single parents of any particular age group, gender and other social and economic demographics due to non-probability sampling. Future investigations can design their samples to amore accurate depiction of demographical ratios, Secondly, a larger sample is likely to bolsterup the intended demographical variety. Besides, self-report measures may inflate or deflate the psychological experiences of these single parents, and further studies may prefer to measure psychological constructs with more robust methods. Moreover, this study was conducted in urban and semi-urban areas of Punjab, lacking rural single parents issues exploration.

\section{CONCLUSION}

This study provided a detailed description of psychological well-being and adjustment in single parents of different socio-economic class in a highly collectivist and family-oriented culture. The study concludes that socio-economic status and economic independence and dependence have a profound impact on the wellbeing and adjustment of single parents. Apart from economic aspects, one of the unique findings of the study is the impact of a social identity as a divorced single parent within a high familyoriented culture that negatively influences their well-being and social adjustment and this seems to influence men and women alike, as this investigation found no gender differences. The study prompts for further phenomenological research 


\section{into the identities and familial relations of single parents.}

\section{CONFLICT OF INTEREST}

\section{There was no conflict of interest to be declared by any author.}

\section{REFERENCES}

1. Waseem J, Muneer R, Hoor-Ul-Ain S, Tariq R, Minhas A. Psychosocial determinants of divorce and their effects on women in Pakistan: a national review. Int J Hum Rights Healthc 2020; 13(4): 299-315.

2. Siflinger $B$. The effect of widowhood on mental health - an analysis of anticipation patterns surrounding the death of a spouse. Health Econ 2017; 26(12): 1505-23.

3. Ennis J, Majid U. The Widowhood effect: explaining the adverse outcomes after spousal loss using physiological stress theories, marital quality, and attachment. Family J 2020; 28(3): 241-46.

4. Watkins NK, Waldron M. Timing of remarriage among divorced and widowed parents. J Divorce Remarriage 2017; 58(4):244-62.

5. Reimann M, Marx CK, Diewald M. Work-to-family and familyto-work conflicts among employed single parents in Germany. Equal Divers Incl 2020; 39(5): 513-31.

6. Amato PR. The Consequences of divorce for adults and children: an update. Drus Istraz 2014; 23(1): 5-24.

7. Maurya AK, Parasar A, Sharma A. The effect of single parent and both parents family on emotional and behavioral problems. Indian J Health Wellbeing 2015; 6(12): 1235.

8. Leopold T. Gender differences in the consequences of divorce: a study of multiple outcomes. Demograp 2018; 55(3): 769-97.
9. Ryff CD, Keyes CLM. The structure of psychological well-being revisited. J Pers Soc Psychol 1995; 69(4): 719.

10. Dufner M, Gebauer JE, Sedikides C, Denissen JJA. Self-Enhancement and Psychological Adjustment: A Meta-Analytic Review. Pers Soc Psychol Rev 2019; 23(1): 48-72.

11. Sabir F. Academic self-concept and achievement among university student as related to their psychological adjustment. Unpubl M Phil Thesis Natl Inst Psychol Quai-E-Azam Univ Islamabad 1999.

12. Stack RJ, Meredith A. The impact of financial hardship on single parents: an exploration of the journey from social distress to seeking help. J Fam Econ Iss 2018; 39(2): 233-42.

13. Min J, Li Y, Xu L, Chi I. Psychological vulnerability of widowhood: financial strain, social engagement and worry about having no care-giver as mediators and moderators. Ageing Soc 2018; 38(11): 2356-75.

14. Brady M. The role of informal childcare in mothers' experiences of care and employment: a qualitative lifecourse analysis. Ed 8. In: Lone parenthood in the life course. Springer, Cham 2018; 237-255.

15. Khaleek SQ, Hussain A. Surge of divorce in lahore, its exploring factors and possible solutions, Pakistan. Adv Soc Sci Res J 2015; 2(5): $1-5$.

16. Monserud MA, Markides KS. Changes in depressive symptoms during widowhood among older Mexican Americans: the role of financial strain, social support, and church attendance. Aging Ment Health 2017; 21(6): 586-94.

17. Abbasi MZ. Women's right to unilateral no-fault based divorce in Pakistan and India. Jindal Glob Law Rev 2016; 7(1): 81-95.

18. Shahid A. Post-divorce maintenance for muslim women in Pakistan and Bangladesh: A Comparative Perspective. Int J Law Policy Family 2013; 27(2): 197-215. 